\title{
ENERGY COST AND CARDIOPULMONARY RESPONSES FOR WHEELCHAIR LOCOMOTION AND WALKING ON TILE AND ON CARPET
}

\author{
By Roger M. Glaser, Ph.D., Michael N. Sawka, Ph.D., Stephen W. Wilde, M.S., \\ Barbara K. Woodrow, M.S. and Agaram G. Suryaprasad, M.D. \\ Laboratory of Applied Physiology, Wright State University School of Medicine, Dayton, \\ Ohio 45435, U.S.A. and the Physiology Research Laboratory, Veterans Administration \\ Medical Center, Dayton, Ohio 45428, U.S.A.
}

\begin{abstract}
The purpose of this study was to compare energy cost and cardiopulmonary responses to wheelchair locomotion and walking on tile and on carpet at $3.0 \mathrm{~km} \cdot \mathrm{h}^{-1}$. Nine wheelchair-dependent (WD) and ten able-bodied (AB) individuals served as test subjects. WD subjects were tested for wheelchair locomotion on tile and on carpet, and AB subjects were tested for walking over both floor surfaces. Studied variables included gross energy cost (GEC), net locomotive energy cost (NLEC), pulmonary ventilation $(\dot{V} E)$ and heart rate (HR) during all test conditions. On tile, GEC and NLEC were found to be lower, whereas $\dot{V} E$ and HR were higher for wheelchair locomotion than for walking. On carpet, wheelchair locomotion elicited higher values for all variables than walking. In going from tile to carpet, significant increases in these variables were found for wheelchair locomotion, whereas walking elicited similar response magnitudes on both floor surfaces. These results suggest that cardiopulmonary stresses for wheelchair locomotion are higher than for walking, and that a carpet can present an obstacle to wheelchair locomotion which may not be recognised by those who walk.
\end{abstract}

Key words: Wheelchair locomotion; Floor surfaces; Energy cost; Cardiopulmonary responses.

\section{Introduction}

INCREASED effort is being directed towards making buildings more accessible to wheelchair-dependent individuals. To eliminate obvious architectural barriers, automatic doors, elevators and ramps are frequently provided. Wheelchair use could be hindered, however, by obstacles which may still remain and are not so obvious. Carpeting has been suggested to be such an obstacle (Brauer, I972; Wolfe et al., I977; Glaser et al., I979). This floor surface, which may require little additional effort to traverse when walking, may indeed be quite stressful for wheelchair locomotion. Since most building interiors are designed by people who can walk, they need to be aware of potential problems that floor surfaces may present to wheelchair users.

To evaluate objectively the relative stresses of wheelchair locomotion on various floor surfaces, it seems advantageous to study physiological responses for this activity in reference to those for walking on the same surfaces. The few studies which directly compared energy cost and cardiopulmonary responses for wheelchair locomotion and walking were performed only on hard level surfaces (Glaser et al., 1975; Glaser et al., 1979). For wheelchair locomotion on carpet, higher stress levels have been suggested due to the greater rolling resistance offered by this surface (Brauer, I972; Wolfe et al., I977; Glaser et al., 1979). Comparative data for walking on hard and carpeted surfaces, however, have not been reported. 
Therefore, the purpose of this study was to compare energy cost and cardiopulmonary responses to wheelchair locomotion and walking on a hard smooth surface and a carpeted surface at an equal velocity.

\section{Subjects}

\section{Methods}

Nine wheelchair-dependent (WD) and ten able-bodied (AB) individuals served as subjects for this study. Mean ( \pm SD) age of both groups was $24 \pm 4 \mathrm{yr}$, and mean weight for WD and $\mathrm{AB}$ groups was $60 \pm 8$ and $66 \pm 8 \mathrm{~kg}$, respectively. The WD subjects had used manual wheelchairs for an average of I 5 years, and their disabilities were primarily lower body in nature. Prior to participation each subject was given a physical examination, informed as to the purpose and procedures of the tests, the extent of their participation, and their right to terminate participation at will without penalty. Each expressed understanding by signing a statement of informed consent. The protocol and procedures of this project were approved by the Medical Human Research Review Committee of Wright State University.

\section{Test Protocol}

Prior to testing, all subjects attended orientation sessions to familiarise themselves with the test wheelchair, instrumentation and procedures. At the beginning of the first test session, subjects sat quietly for $15 \mathrm{~min}$, and rest data were collected during the final $2 \mathrm{~min}$. The WD group then completed two tests in random order: wheelchair locomotion on tile and on carpet at a velocity of $3.0 \mathrm{~km} \cdot \mathrm{h}^{-1}$. Exercise on each floor surface was $5 \mathrm{~min}$ in duration, and was followed by a I0-minute rest period. Physiological data were collected during the final 2 min of each exercise period. The $\mathrm{AB}$ group randomly performed the same locomotive tasks by walking.

\section{Test Courses}

Energy cost and cardiopulmonary responses to wheelchair locomotion and walking were determined on two $107 \mathrm{~m}$ octagonal courses (basement and first floor of the Medical Sciences Building) which were identical except for floor surface. The floor surface of the basement is level smooth hard tile, whereas the floor surface of the first floor is level low pile carpet. Ambient temperature was maintained at about $23^{\circ} \mathrm{C}$ and relative humidity was about 50 per cent.

\section{Specialised Instrumentation}

To standardise conditions, all WD subjects were tested in an Everest and Jennings ${ }^{1}$ Universal model wheelchair with solid rubber tyres (Fig. Ia). Locomotive velocity was set and maintained by a pace cart (Fig. Ib) which was equipped with an electronic speedometer, odometer and timer (Glaser et al., I980a). This pace cart was pushed by a technician directly in front of the test subject. Another technician wearing a Plexiglas board on which data collection instrumentation was mounted (Fig. Ic) followed the test subject. This instrumentation consisted of a 60 L Douglas bag, 3-way valve, cardiotachometer and timer.

\section{Physiological Variables}

Oxygen uptake $\left(\dot{\mathrm{VO}}_{2}\right)$, carbon dioxide output $\left(\dot{\mathrm{V}} \mathrm{CO}_{2}\right)$ and pulmonary ventilation ( $\dot{\mathrm{V} E})$ were determined by open circuit spirometry. Subjects breathed via a 


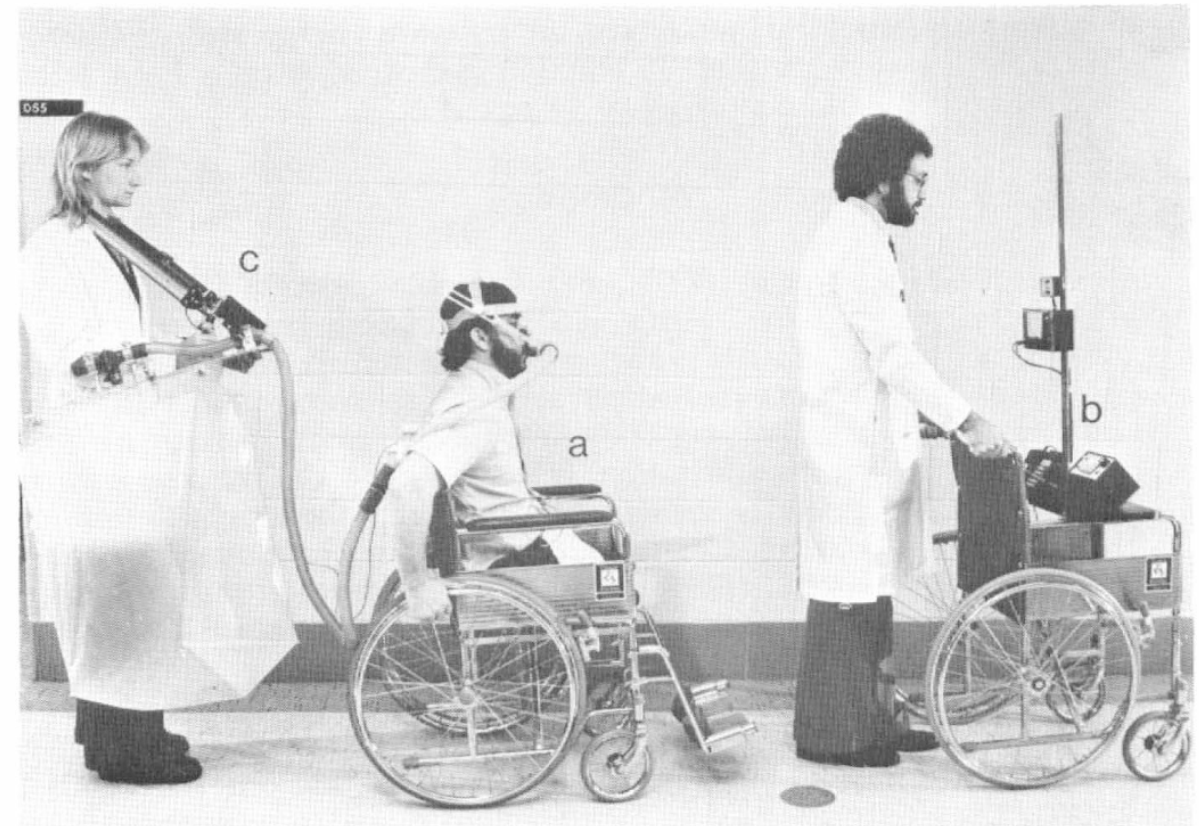

FIG. I

Specialised instrumentation. (a) subject in test wheelchair, (b) pace cart, (c) data collection instrumentation.

2-way breathing valve (Collins ' $\mathrm{J}$ '2) held in place by an adjustable headgear assembly (Fig. Ia). During specified time periods, expired gases were collected in the $60 \mathrm{~L}$ Douglas bag'. Expired gases were then analysed for $\mathrm{O}_{2}$ and $\mathrm{CO}_{2}$ concentration by an electrochemical $\mathrm{O}_{2}$ analyser (Applied Electrochemistry $\mathrm{S}-3 \mathrm{~A}^{3}$ ) and an infra-red $\mathrm{CO}_{2}$ analyser (Beckman $\mathrm{LB}-2^{4}$ ), respectively. Analysers were calibrated before and during testing with room air and reference gases of known concentrations. Expired gas volume was measured by a dry gasometer (Parkinson-Cowan CD-4 ${ }^{5}$ ) calibrated against a I20 L Tissot gasometer ${ }^{2}$.

Energy cost (Kcals) was determined by indirect calorimetry using $\mathrm{V}_{2}$ and respiratory exchange ratio $\left(\dot{\mathrm{V} C O}{ }_{2} \cdot \dot{\mathrm{VO}}{ }_{2}^{-1}\right)$ values. To express energy cost of locomotion (net Kcals) per unit of body weight $(\mathrm{kg})$ per unit of distance travelled $(\mathrm{km})$, net locomotive energy cost (NLEC, net Kcals $\cdot \mathrm{kg}^{-1} \cdot \mathrm{km}^{-1}$ ) was determined by the following computation:

$$
\mathrm{NLEC}=(\mathrm{E}-\mathrm{e})(\mathrm{Wt} \cdot \mathrm{D})^{-1} .
$$

Where $\mathrm{E}$ is the gross caloric output in Kcals, e is the resting caloric output in Kcals, Wt is the weight of the subject in $\mathrm{kg}$, and $\mathrm{D}$ is the distance travelled in $\mathrm{km}$. NLEC provides a relative index inversely related to the efficiency of locomotionthe lower the NLEC the higher the efficiency, and vice versa.

Heart rate was monitored by way of the cardiotachometer (Gedco CT-2 ${ }^{6}$ ) utilising chest electrodes.

\section{Statistical Analysis}

Due to sampling limitations, data from WD subjects during wheelchair locomotion could not be statistically compared to those of $\mathrm{AB}$ subjects for walking. 
Both subject populations served as their own control for locomotion on tile and on carpet. Means, standard deviations, standard errors and dependent $t$ tests were calculated using a programmable calculator (Hewlett-Packard 9815 $\mathrm{A}^{7}$ ). Statistical significance was accepted at the $p<0.05$ level.

\section{Results}

Resting data $(\overline{\mathrm{X}} \pm \mathrm{SE})$ for $\mathrm{WD}$ and $\mathrm{AB}$ subjects, respectively, were: energy cost $=0.98 \pm 0.06, \mathrm{I} \cdot \mathrm{I} 5 \pm 0.09 \mathrm{Kcals} \cdot \mathrm{min}^{-1} ; \dot{\mathrm{VE}}=7 \cdot \mathrm{I} \pm 0.4,7.3 \pm 0.6 \mathrm{~L} \cdot \mathrm{min}^{-1}$; and $\mathrm{HR}=75 \pm 5,65 \pm 4$ beats $\cdot \mathrm{min}^{-1}$. Locomotive data were organised into two primary considerations: (I) WD subjects for wheelchair locomotion on tile $v s$ carpet, and (2) AB subjects for walking on tile vs carpet. Table I presents gross energy cost (GEC), NLEC, $\dot{V E}$ and HR for these comparisons at a locomotive

\section{TABLE I}

Gross Energy Cost (GEC); Net Locomotive Energy Cost (NLEC), Pulmonary Ventilation (VE) and Heart Rate (HR) of Wheelchair-Dependent Individuals $(\mathrm{N}=9)$ for Wheelchair Locomotion (WC), and Able-Bodied Individuals ( $\mathrm{N}=10$ ) for Walking (WK), on Tile and on Carpet at $3 \mathrm{~km} \cdot \mathrm{h}^{-1}$

\begin{tabular}{|c|c|c|c|c|c|}
\hline Variable & Mode & Tile & Carpet & $\% \Delta$ & $P<$ \\
\hline GEC & WC & $2 \cdot 45 \pm 0 \cdot 19$ & $3 \cdot 34 \pm 0.23$ & +36 & 0.01 \\
\hline$\left(\mathrm{Kcal} \cdot \mathrm{min}^{-1}\right)$ & WK & $2 \cdot 92 \pm 0 \cdot 14$ & $2 \cdot 87 \pm 0 \cdot 16$ & -2 & NS \\
\hline $\begin{array}{l}\text { NLEC } \\
\text { (net Kcal } \cdot \mathrm{kg}^{-1} \cdot \mathrm{km}^{-1} \text { ) }\end{array}$ & WC & $0.46 \pm 0.03$ & $0.80 \pm 0.06$ & +74 & 0.01 \\
\hline$\dot{\mathrm{VE}}$ & WC & $I 6 \cdot 3+I \cdot 6$ & $21 \cdot 7+\mathrm{I} \cdot 7$ & +33 & 0.01 \\
\hline$\left(\mathrm{L} \cdot \mathrm{min}^{-1}, \mathrm{BTPS}\right)$ & WK & $15.8 \pm 0.8$ & $15 \cdot 3 \pm 1 \cdot 0$ & $\begin{array}{l}150 \\
-3\end{array}$ & NS \\
\hline $\mathrm{HR}$ & WC & $100 \pm 5$ & II $4 \pm 6$ & $+\mathrm{I} 4$ & 0.01 \\
\hline (beats $\cdot \min ^{-1}$ ) & WK & \pm 4 & \pm 4 & $-I$ & NS \\
\hline
\end{tabular}

Values are $\overline{\mathrm{X}} \pm \mathrm{SE}$

$\% \Delta=$ percentage difference for carpet in reference to tile

$P<=$ level of statistical significance

$\mathrm{NS}=$ not statistically significant

velocity of $3.0 \mathrm{~km} \cdot \mathrm{h}^{-1}$. Also presented are the percentage differences $(\% \Delta)$ for each variable between the two floor surfaces, and the statistical significant probability levels $(P<)$.

\section{Comparison of Modes of Locomotion}

On tile, the WD subjects during wheelchair locomotion were found to have lower GEC and NLEC values, and higher $\dot{V E}$ and $H R$ values than the $A B$ subjects during walking at the same velocity. On carpet, all variables were markedly higher for wheelchair locomotion than for walking.

\section{Comparison of Floor Surfaces}

For wheelchair locomotion, all variables were significantly higher $(P<0.0 \mathrm{I})$ on the carpeted surface. In contrast, no differences for each variable were observed for walking on tile and on carpet. 


\section{Discussion}

Factors which in part influence the magnitude of physiological responses to wheelchair locomotion include: the fitness level of the user (Glaser et al., 1978-79; Glaser et al., I98I), characteristics of the wheelchair used (Hildebrandt et al., I970; Glaser et al., I980c), velocity of locomotion (Glaser et al., I980a; Glaser et al., I980b) and architectural conditions (Brauer, I972; Glaser et al., I980a). This investigation was conducted under what might be considered minimal stress or baseline conditions for wheelchair locomotion. The subjects were young, active college students; the test wheelchair was equipped with narrow hard rubber tyres; the velocity was relatively low; and the floor surfaces were level, smooth tile and low pile carpet.

\section{Comparison of Modes of Locomotion}

Previous research has indicated that wheelchair locomotion on a level hard surface requires less (Hildebrandt et al., I970), similar (Glaser et al., I975; Glaser et al., 1979) and greater (Traugh et al., I975; Wolfe et al., I977) energy expenditure than for walking. These discrepancies could possibly be due to differences in the above mentioned factors, as well as the method of study. Most of these investigations directly determined the energy cost of wheelchair locomotion, but then predicted the energy cost of walking from data in the literature (Hildebrandt et al., 1970; Traugh et al., I975; Wolfe et al., 1977). In an effort to directly compare physiological responses to wheelchair locomotion and walking, Glaser et al. (I979) had able-bodied subjects participate in both activities at velocities of 2.5 to 4.5 $\mathrm{km} \cdot \mathrm{h}^{-1}$. Although no significant differences were found, aerobic metabolism for wheelchair operation was lower at $2.5 \mathrm{~km} \cdot \mathrm{h}^{-1}$, equal at $3.5 \mathrm{~km} \cdot \mathrm{h}^{-1}$ and greater at $4.5 \mathrm{~km} \cdot \mathrm{h}^{-1}$. Therefore, at a normal walking velocity of about $4 \mathrm{~km} \cdot \mathrm{h}^{-1}$, the energy expenditure for wheelchair locomotion appears to be similar or greater than for walking. In agreement with these findings, the present investigation found the energy cost for wheelchair locomotion on tile to be lower than for walking at a velocity of $3 \cdot 0 \mathrm{~km} \cdot \mathrm{h}^{-1}$.

As with aerobic metabolism, Glaser et al. (1979) found $\dot{V E}$ to exhibit a similar crossover effect with locomotive velocity. These data suggest that this occurs at about $3 \mathrm{~km} \cdot \mathrm{h}^{-1}$ on a tile surface. Indeed, the WD and AB subjects in the present study had similar $\dot{V} E$ values for wheelchair locomotion and walking on this surface. On carpet, however, our WD subjects had a markedly higher VE during wheelchair locomotion than the $\mathrm{AB}$ subjects during walking at this velocity.

Since gross energy cost is expressed in Kcal per unit of time, it provides little information as to the metabolic cost of an individual to travel a given distance. NLEC, however, provides an index to express the relative energy cost (corrected for resting metabolism and body weight) per kilometre of distance travelled. Therefore, to facilitate comparison, we propose that this index be used to express the efficiency of various locomotive tasks. The lower NLEC values for wheelchair locomotion indicate that this activity is more efficient than walking for the velocity studied on tile. On carpet, however, the higher NLEC indicated that wheelchair locomotion was less efficient than walking.

Despite the somewhat lower energy cost for wheelchair locomotion than walking on tile, heart rate responses were higher for the WD subjects. Hildebrandt et al. (1970) have indicated that heart rate values for many experienced wheelchair users exceeded those for able-bodied individuals during walking at the same velocity. In addition, data were presented indicating that heart rate responses were 
further increased when patients had additional upper extremity disabilities. Indeed, our WD subjects exhibited higher $\mathrm{HR}$ responses ( 20 and 35 beat $\cdot \mathrm{min}^{-1}$ higher on tile and carpet, respectively) than those exhibited by the AB subjects during walking. These elevated heart rate responses may be indicative of greater cardiovascular stress for WD individuals.

\section{Comparison of Floor Surfaces}

Carpet has been shown to increase rolling resistance, and thus the work rate for wheelchair locomotion (Brauer, I972; Glaser et al., I979; Glaser et al., I980a). In comparison to a hard smooth surface, Brauer (I972) has shown that dense weave and deep pile carpet offer approximately two and three times the rolling resistance, respectively. As expected, wheelchair operation on the low pile carpet markedly increased GEC, NLEC, VE and HR for the WD subjects. It is interesting to note that we intended to use $4 \mathrm{~km} \cdot \mathrm{h}^{-1}$ for this study. However, pilot research showed that our WD subject population experienced excessive fatigue in attempting to maintain this wheelchair velocity on carpet. In contrast to wheelchair locomotion, walking elicited similar values for each physiological variable on tile and carpet. This suggests that because of the nature of walking, it is not adversely affected by carpeted floor surfaces.

This study demonstrates that carpet can markedly increase metabolic and cardiopulmonary stresses for wheelchair locomotion. Since no additional stresses occur for walking on carpet, able-bodied individuals may not realise that this surface represents an obstacle to wheelchair-dependent individuals. This has probably contributed to the widespread use of carpet in many public buildings. It appears that these stresses could potentially limit rehabilitation of wheelchair users and present health hazards to certain individuals.

Acknowledgements. This study was supported in part by the Rehabilitative Engineering Research and Development Service of the Veterans Administration.

\section{RÉSUMÉ}

Le but de cette étude était de mettre en comparaison le coût d'énergie et les réponses cariopulmonaires à la locomotion d'un fauteuil roulant et à la marche à $3 \cdot 0 \mathrm{~km} \cdot \mathrm{h}^{-1}$ sur les carreaux et sur le tapis. Neuf personnes qui dépendaient d'un fauteil roulant (WD) et dix personnes robustes $(\mathrm{AB})$ servaient des sujets des essais. L'on a expérimenté sur les sujets WD pour étudier la locomotion du fauteuil roulant sur les carreaux et sur le tapis, et l'on a expérimenté sur les sujets $\mathrm{AB}$ pour leur étudier à la marche sur tous les deux surfaces de plancher. Les variables étudiées comprenaient le coût d'énergie brut (GEC), le coût d'énergie locomotive net (NLEC), la ventilation pulmonaire ( $\dot{V} E)$, et la fréquence cardiaque (HR) dans toutes les conditions d'essai. Sur les carreaux, l'on a trouvé que le GEC et le NLEC étaient plus bas pour la locomotion du fauteuil roulant que pour la marche, tandis que le $\dot{V E}$ et le HR étaient plus hauts. Sur le tapis, l'on a trouvé que la locomotion du fauteuil roulant a provoqué valeurs plus hautes que pour la marche pour tous les variables. En allant des carreaux au tapis, on a trouvé des augmentations significatives dans ces variables pour la locomotion du fauteuil roulant, tandis qu'au contraire, la marche a provoqué les grandeurs analogues des réponses sur tous les deux surfaces de plancher. Ces résultats suggèrent que les tensions cardiopulmonaires pour la locomotion du fauteuil roulant sont plus hautes que pour la marche, et que le tapis peut être un obstacle à la locomotion des fauteuils roulants dont les personnes qui peuvent marcher ne se rendent pas compte.

\section{ZUSAMMENFASSUNG}

Der Zweck dieser Forschung war es, den Energieaufwand und kardiopulmonale Reaktionen auf Rollstuhl-Bewegung und Gehen mit $3 \cdot 0 \mathrm{~km} \cdot \mathrm{h}^{-1}$ über Fliesen und Teppich- 
böden zu vergleichen. Neun rollstuhl-abhängige (WD) und ro ganz gesund (AB) Personen dienten als Versuchspersonen. WD-Personen wurden in Bezug auf Rollstuhl-Bewegung über Fliesen und Tepichboden erprobt, und AB-Personen wurden in Bezug auf RollstuhlBewegung und Gehen über die beiden Bodenflächen erprobt. Untersuchte Grössen schliessen den ganzen Energieaufwand (GEC), Nutzenergieaufwand fur Bewegung (NLEC), Lungenventilation ( $\dot{\mathrm{V} E})$, und Herzrate (HR) unter allen Versuchsbedingungen ein. Über Fliesen waren GEC and NLEC weniger, während VE und HR grösser waren, für RollstuhlBewegung als für Gehen. Über Teppichböden waren die Werte aller Variablen grösser bei Rollstuhl-Bewegung als beim Gehen. Bei Bewegung von Fliesen auf Teppichböden wurden bedeutende Erhohungen dieser Grössen für Rollstuhl-Bewegung gefunden, während das Gehen ähnliche Reaktionen-Grössen über beide Bodenflächen hervorgerufen hat. Diese Ergebnisse lassen daraus erschliessen, dass kardiopulmonale Anstrengungen für Rollstuhl-Bewegung grösser sind als für Gehen und dass. Teppichböden ein Hindernis für rollstuhl-abhängige Personen sein können, das möglicherwiese von Unbehinderten nicht erkannt wird.

\section{REFERENCES}

Brauer, R. L. (I972). An ergonomic analysis of wheelchair wheeling. Ph.D. Dissertation, Urbana-Champaign, Ill.: University of Illinois.

Glaser, R. M., Collins, S. R., \& Wilde, S. W. (I980a). Power output requirements for manual wheelchair locomotion. In Proceedings of the IEEE National Aerospace and Electronics Conference, New York: Institute of Electrical and Electronic Engineers, pp. 502-509.

Glaser, R. M., Edwards, M., Barr, S. A. \& Wilson, G. H. (I975). Energy cost and cardiorespiratory response to wheelchair ambulation and walking. Fed. Proc., 34, 46I.

Glaser, R. M., Foley, D. M., Laubach, L. L., Sawka, M. N. \& Suryaprasad, A. G. (I978-79). An exercise test to evaluate fitness for wheelchair activity. Paraplegia, 16, 34I-349.

Glaser, R. M., Laubach, L. L., Sawka, M. N. \& Suryaprasad, A. G. (I979). Exercise stress, fitness evaluation and training of wheelchair users. In Proceedings-International Conference on Lifestyle and Health, I978: Optimal Health and Fitness for People with Physical Disabilities, edited by Leon, A. S., and Amundson, G. J. Minneapolis, Minn.: University of Minnesota Press, pp. I67-194.

Glaser, R. M., Barr, S. A., Laubach, L. L., Sawka, M. N. \& Suryaprasad, A. G. (I980b). Relative stresses of wheelchair activity. Human Factors, 22, I77-I8I.

Glaser, R. M., Sawka, M. N., Durbin, R. J., Foley, D. M. \& Suryaprasad, A. G. (I98I). Exercise program for wheelchair activity. Am. F. Phys. Med., 6o, 67-75.

Glaser, R. M., Sawka, M. N., Young, R. E. \& Suryaprasad, A. G. (I980c). Applied physiology for wheelchair design. F. Appl. Physiol.: Respirat. Environ. Exercise Physiol., 48, $4 \mathrm{I}-44$.

Hildebrandt, G., Voigt, E.-D., Bahn, D., Berendes, B. \& Kröger, J. (i970). Energy costs of propelling wheelchair at various speeds : cardiac response and effect on steering accuracy. Arch. Phys. Med. Rehabil., 51, I3I-I36.

Traugh, G. H., Corcoran, P. J. \& Reyes, R. L. (I975). Energy expenditure of ambulation in patients with above-knee amputations. Arch. Phys. Med. Rehabil., 56, 67-7I.

Wolfe, G. A., WATERS, R. \& Hislop, H. J. (I977). Influence of floor surface on the energy cost of wheelchair propulsion. Physical Ther., 57, 1022-1027.

\section{INSTRUMENTATION REFERENCES}

1 Everest \& Jennings, I803 Pontius Avenue, Los Angeles, California 90025.

2 Warren E. Collins, Inc., 220 Wood Road, Braintree, Massachusetts 02184.

${ }^{3}$ Applied Electrochemistry, 735 North Pastoria Avenue, Sunnyvale, California 94086.

4 Beckman Instruments, Inc., Electronic Instruments Division, 3900 North River Road, Schiller Park, Illinois 601 76 .

${ }^{5}$ Dyna Sciences, Division of Whittaker Corporation, Township Line Road, Bluebell, Pennsylvania 19422.

${ }^{6}$ Gedco Associates, I69 East Second Street, Huntington, New York II 746.

${ }^{7}$ Hewlett-Packard, I 50I Page Mill Road, Palo Alto, California 94304. 